\section{O papel da mãe no tratamento de criança com recidiva de câncer}

Wiegand, S. C. B.

Programa de Pós-graduação em Bioética da Pontifícia Universidade Católica do Paraná (PUC-PR). E-mail: swiegand@uol.com.br

\section{Wiegand, B. B}

Programa de Pós-graduação em Bioética da Pontifícia Universidade Católica do Paraná (PUC-PR).

PALAVRAS-CHAVE: bioética, vulnerabilidade, dignidade humana, criança, recidiva, câncer, mãe.

Introdução: $\mathrm{O}$ câncer no Brasil representa a primeira causa de morte $(8 \%$ do total) por doença entre crianças e adolescentes de 1 a 19 anos, segundo o Instituto Nacional de Câncer [1]. Ao mesmo tempo em que pode haver boa chance de sobrevivência quando a doença é detectada precocemente, de outra parte a recidiva do câncer é impactante. Nesse momento de recomeço, a mãe do paciente possui papel de destaque, pois sabe-se que os indivíduos envolvidos nesse contexto são vulneráveis e que prevalecem sentimentos de falta de controle da situação, perplexidade e ansiedade [2]. Percebe-se o caráter multidisciplinar (da psicologia, da bioética, da saúde) e pluralista do assunto, tal como preceituado no artigo $2^{\circ}$ da Declaração Universal sobre Bioética e Direitos Humanos, da UNESCO. Método: a pesquisa proposta tem como fundamento a análise do papel da mãe no tratamento da criança com recidiva de câncer. Trata-se de um ensaio reflexivo sobre o tema, à luz da Declaração Universal sobre Bioética e Direitos Humanos, da UNESCO. Resultados: Diante do cenário de desconhecimento e incertezas, muitas vezes a mãe é deixada de lado, ficando apenas observando procedimentos médicos que vão além de sua compreensão. Uma consequência verificada pela literatura, seja no momento do diagnóstico, no itinerário terapêutico, ou em havendo recidiva, é o chamado luto antecipatório da mãe pela doença do seu filho. Quando a doença é diagnosticada sem possibilidade de cura, não é raro os familiares se culparem por ela, mesmo que não tenham culpa sobre a enfermidade [3]. Eles se sentem responsáveis pela biografia de seus filhos. Eventual falecimento da criança no curso do tratamento pode se tornar uma perda muito difícil, pois há a inversão da ordem natural: pais enterrando seus filhos e não os filhos enterrando os seus país [4]. Dessa forma, fala-se em respeito à dignidade humana, não apenas com relação ao paciente, mas no tocante à mãe, sendo objetivo (artigo $2^{\circ}$, c) e princípio $\left(\operatorname{artigo} 3^{\circ}\right.$ ) da Declaração Universal sobre Bioética e Direitos Humanos, da UNESCO [5]. Conclusões: A comunicação entre equipe de saúde, família e a própria criança, quando possível, pode ser uma ferramenta que permite saber os porquês de exames, tratamentos, consequências. O momento é de incertezas e o respeito pela vulnerabilidade humana deve imperar. O acolhimento das inquietações é benéfico para todos os envolvidos, como uma estratégia para favorecer o enfrentamento da doença. Além disso, a atuação de equipe multiprofissional poderá ser útil para abranger diferentes questões relacionadas ao sofrimento do paciente e de sua familia, sobretudo quando analisado o papel da mãe no tratamento de criança com recidiva de câncer.

AGRADECIMENTOS: O presente trabalho foi realizado com apoio da Coordenação de Aperfeiçoamento de Pessoal de Nível Superior - Brasil (CAPES) - Código de Financiamento 001.

\section{REFERÊNCIAS}

[1] Brasil. Instituto Nacional de Câncer. Disponível em: $<$ http://www2.inca.gov.br/wps/wcm/connect/tiposdecancer/si te/home/infantil >. Acesso em: 28 de setembro de 2018.

[2] Arruda-Colli, M. N. F., Lima, R. A. G., Perina, E. M., Santos, M. A. A recidiva do câncer pediátrico: um estudo sobre a experiência materna. Pscicologia USP. Volume 27, número 2, p. 307-314. (2016).

[3] Kübler-Ross, E. (2008). Sobre a morte e o morrer: o que os doentes terminais têm para ensinar a médicos, enfermeiras, religiosos e aos próprios parentes. 9. ed. São Paulo: Martins Fontes. (2005).

[4] D’Assumpção, E. A. Sobre o viver e o morrer - Manual de Tanatologia e Biotanatologia para os que partem e os que ficam. Petrópolis, Rio de Janeiro: Editora Vozes. (2010).

[5] UNESCO. Declaração Universal sobre Bioética e Direitos Humanos. Adaptada por aclamação no dia 19 de Outubro de 2005 pela $33^{\mathrm{a}}$ sessão da Conferência Geral da UNESCO. Disponível em: $<$ http://unesdoc.unesco.org/images/0014/001461/ 146180por.pdf $>$. 